\title{
Range and heterogeneity of outcomes in randomized trials of pediatric chronic kidney disease
}

Lauren SH Chong ${ }^{1,2}$, Benedicte Sautenet, $\mathrm{PhD}^{1,2,3,4,5}$, Allison Tong, $\mathrm{PhD}^{1,2}$, Camilla S Hanson, BPsych (Hons) ${ }^{1,2}$, Susan Samuel, MD ${ }^{6}$, Michael Zappitelli, MD ${ }^{7}$, Allison Dart, MD ${ }^{8}$, Susan Furth, PhD ${ }^{9}$, Allison A Eddy, MD ${ }^{10}$, Jaap Groothoff, $\mathrm{PhD}^{11}$, Nicholas JA Webb, MD ${ }^{12}$, HuiKim Yap, MD ${ }^{13}$, Detlef Bockenhauer, $\mathrm{PhD}^{14}$, Aditi Sinha, MD ${ }^{15}$, Stephen I Alexander, $\mathrm{PhD}^{2}$, Stuart L Goldstein, MD ${ }^{16}$, Debbie S Gipson, MD ${ }^{17}$, Gayathri Raman, MBBS ${ }^{1}$, Jonathan C Craig, $\mathrm{PhD}^{1,2}$

\section{Author affiliations:}

${ }^{1}$ Sydney School of Public Health, The University of Sydney, Sydney, Australia

${ }^{2}$ Centre for Kidney Research, The Children's Hospital at Westmead, Westmead, Sydney,

Australia

${ }^{3}$ University Francois Rabelais, Tours, France

${ }^{4}$ Department of Nephrology and Clinical Immunology, Tours Hospital, Tours, France

${ }^{5}$ INSERM, U1153, Paris, France

${ }^{6}$ Department of Pediatrics, Section of Nephrology, University of Calgary, Calgary, Canada

${ }^{7}$ Department of Pediatrics, Division of Pediatric Nephrology, Montreal Children's Hospital,

McGill University Health Centre, McGill University, Montreal, Canada

${ }^{8}$ Department of Pediatrics and Child Health, The Children's Hospital Research Institute of

Manitoba, University of Manitoba, Winnipeg, Canada

${ }^{9}$ Departments of Pediatrics and Epidemiology, Perelman School of Medicine and Division of

Nephrology, The Children's Hospital of Philadelphia, Philadelphia, Pennsylvania, United States

${ }^{10}$ Department of Pediatrics, University of British Columbia and the British Columbia Children's

Vancouver, Canada

${ }^{11}$ Department of Pediatric Nephrology, Emma Children's Hospital AMC Academic Medical

Center, Amsterdam, The Netherlands

${ }^{12}$ Department of Pediatric Nephrology and NIHR/Wellcome Trust Clinical Research Facility,

University of Manchester, Manchester Academic Health Science Centre, Royal Manchester

Children's Hospital, Manchester, UK

${ }^{13}$ Department of Pediatrics, Yong Loo Lin School of Medicine, National University of Singapore

,Singapore

${ }^{14}$ UCL Centre for Nephrology and Great Ormond Street Hospital for Children NHS Foundation

Trust, London, United Kingdom

${ }^{15}$ Division of Nephrology, Department of Pediatrics, All India Institute of Medical Sciences, India

${ }^{16}$ Division of Nephrology and Hypertension, Cincinnati Children's Hospital Medical Center,

Cincinnati, Ohio, United States

${ }^{17}$ Department of Pediatrics, School of Medicine, University of Michigan, Ann Arbor, United States

Corresponding author/reprint request author: Allison Tong, Centre for Kidney Research, The Children's Hospital at Westmead, Westmead NSW 2145, Australia

Tel: +61 298451467 Fax: +61 298451491 Email: allison.tong@sydney.edu.au

Short title: Outcomes in trials in children with CKD

Keywords: Children, systematic review, chronic kidney disease, outcomes

Funding source: No funding was secured for this study. AT is supported by the National Health and Medical Research Council Fellowship (1106716)

Conflict of interest: The authors have no conflicts of interest relevant to this article to disclose 


\begin{abstract}
Objective: To determine the range and heterogeneity of outcomes reported in randomized controlled trials (RCTs) of interventions for children with chronic kidney disease (CKD).

Study Design: The Cochrane Kidney and Transplant Specialized Register was searched to March 2016. Randomized trials involving children across all stages of CKD were selected. All outcome domains and measurements were extracted from included trials. The frequency and characteristics of the outcome domains and measures were evaluated.
\end{abstract}

Results: From 205 trials included, 6158 different measurements of 100 different outcome domains were reported, with a median of 22 domains per trial (interquartile range [IQR] 13 to 41 ). Overall, 52 domains (52\%) were surrogate, 38 (38\%) were clinical, and $10(10 \%)$ were patientreported. The five most commonly reported domains were blood pressure (76 [37\%] trials), relapse/remission (70 [34\%]), kidney function (66 [32\%]), infection (61 [30\%]), and height/pubertal development (51 [25\%]). Mortality (14\%), cardiovascular disease (4\%) and quality of life (QOL) (1\%) were reported infrequently. The two most frequently reported outcomes, blood pressure and relapse/remission, had 56 and 81 different outcome measures, respectively.

Conclusions: The outcomes reported in clinical trials involving children with CKD are extremely heterogeneous and are most often surrogate outcomes, rather than clinical and patient-centered outcomes such as cardiovascular disease and QOL. Efforts to ensure consistent reporting of outcomes that are important to patients and clinicians will improve the value of trials to guide clinical decision-making. In our study, non-English articles were excluded. 


\section{Introduction}

Since the recognition of children as "therapeutic orphans" in the 1960s,(1) there has been a wave of international efforts to improve trial-based evidence to support the use of health interventions in the pediatric setting.(1-12) The past two decades has seen an increase in the number of trials conducted in children since the United States and Europe revised legislation on labelling of medicines to mandate pediatric data. ${ }^{3}$ Also, major pediatric trial networks have been established globally, including the US National Institute of Child Health and Human Development Pediatric Trial Network and the Network of Pediatric Research at the European Medicines Agency, to improve infrastructure and capacity for pediatric trials. $(13,14)$

Despite this upsurge in pediatric clinical trials, the relevance and value of trials may be limited by problems in the prioritization, design, reporting and dissemination of research, including outcomes measured and reported.(15-21) Trials are only as informative as their outcomes,(22) yet many report outcomes that may not be directly relevant to patients and clinicians, and do not involve children and caregivers in the selection of outcomes.(23-25) Analyses of pediatric trials within specific health conditions have shown that the outcomes reported are extremely variable, including the definitions and measures used(23-27), which limits comparability of the effectiveness of interventions across studies.(16) Initiatives to establish core outcomes, to be reported at a minimum in all trials with specific health condition, such as The Outcome Measures in Rheumatology (OMERACT), have demonstrated improvement in the relevance and reporting of outcomes in trials, $(22,23,28-30)$ though core outcome sets are generally lacking in the pediatric setting.

Children with chronic kidney disease (CKD) have a mortality rate up to 30-times higher than the age-matched general population, and those who progress to end-stage kidney disease depend on 
dialysis or a kidney transplant for survival.(31, 32) Although many trials have been conducted in children with CKD, the risk and prevalence of comorbid conditions, treatment complications, developmental problems, debilitating symptoms, such as fatigue, and impaired quality of life (QOL) remain high.(33-44) Improvements in health care and outcomes through research rely on the relevance and consistency of outcomes reported in trials in this vulnerable population. Affected children depend on their caregivers and clinicians to provide long-term, complex, and highly technical treatments that have profound implications for their development and well-being. We aimed to describe the scope and consistency of outcome domains and measures in trials involving children with all stage of $\mathrm{CKD}$, to inform strategies for establishing core outcomes that are important to children, families and clinicians to be reported in trials, to inform clinical decision making and ultimately to improve the outcomes for children with CKD.

\section{Methods}

\section{Selection criteria}

We searched the Cochrane Kidney and Transplant Specialized Register for all randomized controlled trials (RCT) involving children aged up to 21 years or less (the upper age limit to define the pediatric population is up to 21 years in the United States(45)) with any CKD diagnosis and at treatment stage (CKD Stage 1-5 [not on renal replacement therapy], 5D [hemodialysis or peritoneal dialysis] and 5T [kidney transplant]) up to March 2016 (Figure 1 (online)). We used search terms relating to children and pediatrics. Trials that included more than $50 \%$ of patients aged above 21 years were excluded. Trials that included children with chronic conditions, but did not report data from the CKD population, were not eligible.

\section{Data extraction}


We extracted the following trial characteristics from each trial: publication year, setting (participating countries), sample size, mean age of participants, study duration, intervention type, and all outcomes. We defined outcome measures as any measures reported separately for all trial arms. We extracted all specifications of the outcome measures, if reported, including the: outcome domain (e.g. blood pressure), specific measurement (e.g. percentage of hypertensive patients), method of aggregation (e.g. percentage change), specific metric (between commencement and end of the trial), and time point of measurement (defined as the time frame from trial commencement to when the outcome was measured).(46)

Analysis

We categorized all the outcome measures from all the included trials into outcome domains. The first author (LC) drafted the initial list of outcome domains. This was cross-checked by four reviewers and revised until consensus was achieved (AT, BS, GR, JCC). The outcome measures were then grouped according to the final list of outcome domains, which was re-reviewed by the same four reviewers. All outcome domains were further categorized as surrogate (biochemical or physiological outcomes i.e. pathophysiological manifestations of health conditions, including such as blood pressure(47)), clinical (medical outcome of a condition or treatment), and patientreported (outcomes reported on by patients and caregivers, typically related to how the patients function or feel in relations to a health condition or therapy), based on standard nomenclature.(48)'(49) Some outcome domains included measures that straddled several categories - surrogate, clinical and patient-reported. Thus, classification of the domains was based on the largest proportion of outcome measures. The number of trials, and dialysis- and transplantation-specific trials that reported each outcome domain were calculated. 
We conducted a detailed analysis of outcome measures of the three outcome domains in each category that were reported most frequently across trials, as well as the three pediatric-specific domains (height and pubertal development, weight/BMI/body composition and school performance). The measurement, aggregation, metric and timing as reported in the primary studies were analyzed. We retained the original term if studies did not further define or provide details on the outcome measure. Statistical analyses of frequency were conducted using $\mathrm{R}$ version 3.2.3 (R Foundation for Statistical Computing, Vienna, Austria, URL http://www.R-project.org/).

\section{Results}

\section{Characteristics of trials}

Our search yielded 1266 trials, of which 205 included 2174 children with CKD (Table 1). The trial characteristics are shown in Table 1. Overall about half of trials involved children with CKD Stage 1 to 5 (123 [52.1\%] trials), 32 [13.6\%]) trials involved patients on hemodialysis, 40 [16.9\%] involved peritoneal dialysis, and $41(17.4 \%)$ involved kidney transplant recipients. The setting of the trials spanned 43 countries, including the United States (51 [25\%] trials), India (18 [9\%]), Japan (15 [7\%]), Germany (14 [7\%]), and England (14 [7\%]); and $28(14 \%)$ trials were multinational. The trials were published from 1970 to 2015 . The median trial duration was 12 months (interquartile range [IQR] 6 to 24 months), and the median sample size was 40 patients (IQR 22 to 76 patients), with only six (2.9\%) larger than 200.

\section{Outcome measures and outcome domains}

Across 205 trials, 6158 outcome measures were reported. The number of outcome measures per trial (including time points of measurement) ranged from 1 to 145, with a median of 22 per trial (IQR 13 to 41). The number of unique outcome measures per trial (excluding time points) ranged 
from 1 to 64 , with a median of 15 (IQR 9 to 26). We excluded 382 outcome measures because they were not a direct health outcome measured in patients (e.g. "mean cold ischemia time," and "medication dose/use/duration") or were specific to a single intervention within a trial (e.g. "number of patients monitored and educated"). The remaining 5776 were classified into 100 outcome domains and these were grouped into: surrogate (52 [52\%]), clinical (38 [38\%]) and patient-reported outcomes (10 [10\%]) (Table 2, 3, 4; online). Nine outcome domains were specific to transplantation, and four were specific to dialysis.

Frequency of outcome domains reported in trials

Figure 2 depicts the proportion of trials that reported each outcome domain. The six most commonly reported outcome domains were: blood pressure (76 [37.1\%] trials), relapse/ remission (70 [34.1\%]), kidney function (66 [32.2\%]), infection (61 [29.8\%], height/pubertal development (51 [24.9\%]) and weight/body mass index/body composition (50 [24.4\%]). Mortality and cardiovascular disease were reported in $28(13.7 \%)$ and $8(3.9 \%)$ of trials, respectively. Depression and QoL (global) were reported in 2 (1.0\%) of trials, and school performance was reported in $1(0.5 \%)$ of trial. Table 5 details the proportion of trials that reported the 10 most frequent outcome domains, and the proportion of trials reporting each outcome domain.

The number of trials that reported a minimum of one surrogate outcome domain was $180(87.8 \%)$, and $164(80.0 \%)$ and $49(23.9 \%)$ reported at least one clinical and one patient-reported domain, respectively. From the 30 (30\%) outcomes reported by at least $10 \%$ of trials, 17 were surrogate, 12 were clinical and one was patient-reported.

Outcome measures and time points 
Figure 3 shows the number of outcome measures and time points of measurement for 10 outcome domains (the three most frequently reported surrogate and clinical outcome domains, two most frequently reported patient-reported domains, and two pediatric-specific domains). The outcome measures and time points of measurement for each outcome domain listed in Figure 3, excluding "school performance" are shown in Figure 4a-i; online.

The three most frequently reported surrogate outcomes were "blood pressure" (56 outcome measures [168 including different time points]; Figure 4b; online), "relapse/remission (82 [240 including time points]; Figure 4c; online) and "kidney function" (47 outcome measures [173 including time points]; Figure 4a; online). The clinical outcomes of "infection", "height and pubertal development" and “dermatologic disorder” had 114 (165 including time points), 34 (137 including time points) and 24 (52 including time points) different outcome measures, respectively (Figure 4d-f; online). For patient-reported outcomes, "pain” (Figure 4g; online) and "psychological impact" (Figure 4h; online) had 27 (50 including time points) and 10 (15 including time points) measures, respectively. There were two pediatric-specific outcomes, "weight/body mass index/body composition" and "school performance". The former had 40 (114 including time points) (Figure 4i; online), and the latter had only one outcome measure, at one time point.

\section{Characteristics of primary outcomes}

Across the 205 trials, 109 (53.2\%) did not specify the primary outcome, 68 (33.2\%) specified several outcomes as primary outcomes, and 28 (13.6\%) specified one unique primary outcome. The outcomes specified as primary outcomes corresponded to 36 different outcome domains: 24 $(66.7 \%)$ were surrogate outcomes, $10(27.8 \%)$ were clinical outcomes and $2(5.6 \%)$ were patient reported outcomes. The 6 most frequently reported primary outcomes were "relapse/ remission" (43 [44.8\%] trials), "proteinuria, albuminuria" (22 [22.9\%] trials), "kidney function" (18 [18.8\%] trials), "height and pubertal development" (15 [15.6\%] trials), "anemia/hemoglobin/iron" (9 
[9.4\%] trials) and bone density/markers" (6 [6.3\%] trials). Table 6; online details the primary outcome domains, and the proportion of trials reporting each one.

\section{Discussion}

Biochemical surrogate outcomes comprised over half of the outcome domains reported in clinical trials involving children with CKD with blood pressure, kidney function, weight and urine protein being the most frequently reported. These were much more common compared with clinical and patient-centered outcomes such as mortality (14\%), cardiovascular disease (4\%), and QOL (1\% of trials). In terms of pediatric-specific outcomes, physical development (height and pubertal development, weight/BMI/body composition) were reported in more than $25 \%$ of trials, but school performance was assessed in only one trial. Thus, the relevance of current trials to guide treatment decisions based on outcomes that are important to children with CKD and their caregivers may be disputable. Also, there is wide heterogeneity of outcome domains reported across trials and, within each outcome domain, large variability in the definitions, time points, and measures used. Such inconsistencies in outcome reporting obscure assessments about the comparative effectiveness of interventions across trials.

Surrogate outcomes, such as serum biomarkers, are frequently used in trials because they require a smaller sample size, shorter time-frame, and fewer resources to evaluate treatment effectiveness. These may be key considerations given the relatively small population of children with CKD, and the additional ethical and logistical requirements to conduct trials in children. However, surrogate outcomes have not been robustly validated in this setting and do not bear direct relevance to patients and their families. Serum phosphate, serum calcium, parathyroid hormone and anemia/hemoglobin/iron were reported in more than $15 \%$ of trials but there is no evidence to indicate that they predict mortality and cardiovascular events in patients with CKD.(49-55) While some physiological markers may be appropriate measures of short-term disease activity for acute 
conditions,(56) they are arguably less informative in chronic conditions. Further studies are needed to validate surrogate outcomes such as parathyroid hormone, serum phosphate and serum calcium.

Many outcomes that have been identified as important and clinically relevant to children with CKD were absent in most trials. Studies that have directly elicited perspectives from children living with CKD have identified their priorities as school attendance and performance, anxiety, social participation, ability to participate in physical activity, hospitalization, and fatigue.(42, 5661) However, patient-reported outcomes constituted only $10 \%$ of all outcome domains reported, and were infrequently reported. Psychological problems, including depression, were reported in less than $10 \%$ of trials. School performance, fatigue, physical function and QOL were reported in just $1 \%$ of trials. No trials reported on social participation. The omission of outcomes important to children with CKD can hamper efforts to implement interventions and strategies to optimize outcomes that are meaningful to patients themselves. Further work is needed to identify dimensions of QOL that are important to patients and subsequently develop feasible and validated measures to use in trials.

There was also a paucity of outcomes identified as important to parents, who have a central role in monitoring and managing the health and treatment of their child with CKD. Physical, cognitive, and social-emotional development have been identified as a major parental concern. $(56,61)$ Linear growth (height and pubertal development and weight/BMI/body composition) were both reported in more than $25 \%$ of trials. However, no trials reported on neurocognitive development. Furthermore, parents share their children's concerns regarding school performance, social participation and mortality, all of which were underreported.(56, 61) We acknowledge that mortality rates are low in the pediatric population. However, the omission of outcomes that are of explicit importance to children and parents can diminish the relevance of trials. 
Some outcomes were specific to certain stages of treatment. For example, graft function, graft loss, chronic graft rejection, graft histology/pathology, malignancy were specific to transplantation, while dialysis adequacy and vascular access complications were specific to dialysis. Many outcomes identified as clinically relevant to children undergoing dialysis or with a kidney transplant were also absent in most trials. In the 55 dialysis-specific trials, four of the five most commonly reported outcomes were surrogate markers (phosphate (21 [38.2\%] dialysis specific trials), parathyroid hormone (18 [32.7\%]), calcium (18 [32.7\%]), bone density/markers (17 [31.0\%]), and one was clinical (infection (17 [31.0\%]). However, the primary concerns of children undergoing dialysis have been identified to be related to social participation, fatigue, school performance and exercise capacity and height.(60) Height/pubertal development was reported in only 7 (16\%) dialysis-specific trials, and school performance and exercise capacity were reported in only one. Social participation and fatigue were not reported at all in dialysisspecific trials.

Among the 41 transplant-specific trials, the five most commonly reported outcomes were all surrogate outcomes: graft function (30 [73.2\%] transplant-specific trials), acute graft rejection (20 [48.8\%]), graft loss (19 [46.3\%]), height and pubertal development (18 [44.0\%]) and blood pressure (17 [41.5\%]). Graft survival and physical side effects (e.g. changes in appearance) have been identified by pediatric kidney transplant recipients as important.(62) However, mortality was reported in only 14 [38\%] transplant-specific studies, and physical side-effects and symptoms including weight gain (11 [30\%]), pain (4 [10.8\%]), and hyperhydrosis (1 [0.5\%]) were rarely reported.

We have also demonstrated substantial multiplicity and inconsistency in outcome domains and measures across trials in children with CKD, with 6158 outcome measures and time points reported across the 100 outcome domains. Blood pressure (the most frequently reported outcome) was measured in $37 \%$ of trials, however had 56 different outcome measures. Without consistency 
in the way outcomes are measured and reported, it is difficult to assess the relative effect of interventions across studies.(63) Furthermore, the majority of trials had a duration less than 24 months (63.4\%) and a small sample size of 1-50 patients (62\%), leading to considerable imprecision regarding treatment effects and uncertainty on the long-term impact of any treatment decisions.

A number of other studies have systematically evaluated the reporting of outcome domains in trials of pediatric conditions such as asthma,(56) autism,(64) appendicitis,(65) acute diarrheal illness,(26) neurodisability,(66) cerebral palsy(67) and otitis media.(68) These reviews have identified similar problems in outcome reporting. There is a dominance of clinical and physiological markers of short-term disease activity, and in contrast limited focus of QOL, functional status and long-term outcomes. Previous studies have also demonstrated a marked inconsistency across trials in the way that outcomes are measured and reported, non-uniformity in the definitions of clinical events used as endpoints, a lack of clarity in reporting methods, and problems with reporting bias.(24-26, 56, 64, 65)

This work provides a comprehensive and detailed analysis of the range and consistency of outcome domains and measures reported in trials in children across all stages of CKD. However, this review has some potential limitations. We used Cochrane reviews as a sampling frame as it was not feasible to include all trials, however the reviews cover the topics of importance in the field. We did not appraise the risk of bias in the included trials given our focus on the reporting of outcomes - not the results. Non-English trials were excluded and most studies were conducted in high-income countries.

Our findings emphasize the importance of developing a minimum set of core outcomes to be measured and reported in RCTs. Core outcome sets increase the likelihood that important outcomes will be measured, improve evidence synthesis by reducing heterogeneity between 
studies, and reduce outcome reporting bias.(56) Core outcome sets have been developed for other medical conditions and the Core Outcome Measures in Effectiveness Trials (COMET) database(69) contains over 120 studies on the development of core outcome sets. However, studies in the pediatric setting are scarce although work has been done in the areas of otitis media,(61, 68) asthma,(56) neurodisability,(66) autism,(64) and cerebral palsy.(67) No core outcome set exists in pediatric CKD.

The Standardized Outcomes in Nephrology (SONG) Initiative, which commenced in 2014, aims to established a core outcome set across the spectrum of CKD that is based on the shared priorities of all stakeholders.(70) SONG-Kids is now underway, engaging children, parents and health professionals in a process to develop a core outcome set for trials in children and adolescents across all stages of CKD.(71)

There is a clear dominance of surrogate outcomes reported in trials in children with CKD, whilst outcomes that have direct relevance for children, their parents and clinicians are relatively rare. Furthermore, the heterogeneity and inconsistency in the way outcomes are defined, assessed and measured also limits ability to synthesize results across studies, including those assessing similar interventions. This reiterates an urgent need to improve the relevance and reliability of trials in decision making through the development of a core outcomes set to be reported as a minimum in trials in children with CKD. A core outcome set can be expected to improve outcome reporting in trials and subsequently lead to enhanced QOL, treatment satisfaction, and health outcomes of children and adolescents with CKD. 


\section{References}

[1] Shirkey H. Therapeutic orphans. J Pediatr 1968; 72:119-20.

[2] Cohen E, Uleryk E, Jasuja M, Parkin PC. An absence of pediatric randomized controlled trials in general medical journals, 1985-2004. J Clin Epidemiol 2007; 60:118-23.

[3] Joseph PD, Craig JC, Caldwell PHY. Clinical trials in children. Br J Clin Pharmacol 2015; 79:357-69.

[4] Smyth RL. Making a difference: the clinical research programme for children. Arch Dis Child 2007; 92:835-7.

[5] National Institutes of Health. NIH policy and guidelines on the inclusion of children as participants in research involving human subjects. 1998.

[6] International Pediatric Association. IPA Statement on equity and quality healthcare for children of the world. 2006.

[7] World Health Organisation. Medicines for children: Resources, progress reports and scientific publications: medicines: medicines for children. Fact sheet $\mathrm{N}^{\circ} 34,1$ June. 2010.

[8] Bellanti F, Della Pasqua O. Modelling and simulation as research tools in paediatric drug development. Eur J Clin Pharmacol 2011; 67 Suppl 1:75-86.

[9] Schreiner MS. Paediatric clinical trials: redressing the imbalance. Nat Rev Drug Discov 2003; 2:949-61.

[10] Wilson JT. An update on the therapeutic orphan. Pediatr 1999; 104:585-90.

[11] Klassen TP, Hartling L, Hamm M, van der Lee JH, Ursum J, Offringa M. StaR Child Health: an initiative for RCTs in children. Lancet 2009; 374:1310-2.

[12] Sammons HM, Gray C, Hudson H, Cherrill J, Choonara I. Safety in paediatric clinical trials-a 7-year review. Acta paediatrica (Oslo, Norway : 1992) 2008; 97:474-7.

[13] Benjamin D. Clinical Trials Approach and the Pediatric Trials Network. American Society for Clinical Pharmacology and Therapeutics (ASCPT) conference, 12-17 March 2012.

[14] Ruperto N, Martini A. Networking in paediatrics: the example of the Paediatric

Rheumatology International Trials Organisation (PRINTO). Arch Dis Child 2011; 96:596-601.

[15] Al-Shahi Salman R, Beller E, Kagan J, Hemminki E, Phillips RS, Savulescu J, et al.

Increasing value and reducing waste in biomedical research regulation and management. Lancet 2014; 383:176-85.

[16] Chalmers I, Bracken MB, Djulbegovic B, Garattini S, Grant J, Gulmezoglu AM, et al. How to increase value and reduce waste when research priorities are set. Lancet 2014; 383:156-65.

[17] Chalmers I, Glasziou P. Avoidable waste in the production and reporting of research evidence. Lancet 2009; 374:86-9.

[18] Chan AW, Song F, Vickers A, Jefferson T, Dickersin K, Gotzsche PC, et al. Increasing value and reducing waste: addressing inaccessible research. Lancet 2014; 383:257-66.

[19] Ioannidis JP, Greenland S, Hlatky MA, Khoury MJ, Macleod MR, Moher D, et al. Increasing value and reducing waste in research design, conduct, and analysis. Lancet 2014; 383:166-75.

[20] Macleod MR, Michie S, Roberts I, Dirnagl U, Chalmers I, Ioannidis JPA, et al. Biomedical research: increasing value, reducing waste. Lancet; 383:101-4.

[21] Isaac A, Saginur M, Hartling L, Robinson JL. Quality of reporting and evidence in American Academy of Pediatrics guidelines. Pediatr 2013; 131:732-8.

[22] Tugwell P, Boers M, Brooks P, Simon L, Strand V, Idzerda L. OMERACT: An international initiative to improve outcome measurement in rheumatology. Trials 2007; 8:1-6.

[23] Sinha I, Jones L, Smyth RL, Williamson PR. A Systematic Review of Studies That Aim to Determine Which Outcomes to Measure in Clinical Trials in Children. PLoS Medicine 2008; 5:e96.

[24] DeMauro SB, Giaccone A, Kirpalani H, Schmidt B. Quality of reporting of neonatal and infant trials in high-impact journals. Pediatr 2011; 128:e639-44.

[25] Anttila H, Malmivaara A, Kunz R, Autti-Ramo I, Makela M. Quality of reporting of randomized, controlled trials in cerebral palsy. Pediatr 2006; 117:2222-30. 
[26] Johnston BC, Shamseer L, da Costa BR, Tsuyuki RT, Vohra S. Measurement issues in trials of pediatric acute diarrheal diseases: a systematic review. Pediatr 2010; 126:e222-31.

[27] Rubin T, Clayton J, Adams D, Jou H, Vohra S. Systematic review of outcome measures in trials of pediatric anaphylaxis treatment. BMC Pediatr 2014; 14:158-.

[28] European Medicines Agency. Paediatric Medicines: Overview. 2016.

[29] National Institute of Health. Best Pharmaceuticals for Children Act (BPCA) Activities at the Eunice Kennedy Shriver National Institute of Child Health and Human Development (NICHD). 2016.

[30] Johnston BC, Shamseer L, Costa BR, Tsuyuki RT, Vohra S. Measurement issues in trials of pediatric acute diarrheal diseases: a systematic review. Pediatr 2010; 126.

[31] McDonald SP, Craig JC. Long-Term Survival of Children with End-Stage Renal Disease. N Engl J Med 2004; 350:2654-62.

[32] Carey WA, Martz KL, Warady BA. Outcome of Patients Initiating Chronic Peritoneal Dialysis During the First Year of Life. Pediatr 2015; 136:e615-22.

[33] Davis ID, Greenbaum LA, Gipson D, Wu LL, Sinha R, Matsuda-Abedini M, et al.

Prevalence of sleep disturbances in children and adolescents with chronic kidney disease. Pediatr Nephrol 2012; 27:451-9.

[34] Gerson AC, Wentz A, Abraham AG, Mendley SR, Hooper SR, Butler RW, et al. Healthrelated quality of life of children with mild to moderate chronic kidney disease. Pediatr 2010; 125:e349-57.

[35] Haavisto A, Korkman M, Holmberg C, Jalanko H, Qvist E. Neuropsychological profile of children with kidney transplants. Nephrol Dial Transplant 2012; 27:2594-601.

[36] Hooper SR, Gerson AC, Johnson RJ, Mendley SR, Shinnar S, Lande MB, et al.

Neurocognitive, Social-Behavioral, and Adaptive Functioning in Preschool Children with Mild to Moderate Kidney Disease. J Dev Behav Pediatr 2016; 37:231-8.

[37] Lande MB, Gerson AC, Hooper SR, Cox C, Matheson M, Mendley SR, et al. Casual blood pressure and neurocognitive function in children with chronic kidney disease: a report of the children with chronic kidney disease cohort study. Clin J Am Soc Nephrol 2011; 6:1831-7.

[38] Lopes M, Ferraro A, Koch VH. Health-related quality of life of children and adolescents with CKD stages 4-5 and their caregivers. Pediatr Nephrol 2014; 29:1239-47.

[39] Moreira JM, Bouissou Morais Soares CM, Teixeira AL, Simões E Silva AC, Kummer AM. Anxiety, depression, resilience and quality of life in children and adolescents with pre-dialysis chronic kidney disease. Pediatr Nephrol 2015; 30:2153-62.

[40] Roumelioti ME, Wentz A, Schneider MF, Gerson AC, Hooper S, Benfield M, et al. Sleep and fatigue symptoms in children and adolescents with CKD: a cross-sectional analysis from the chronic kidney disease in children (CKiD) study. Am J Kidney Dis 2010; 55:269-80.

[41] Tong A, Lowe A, Sainsbury P, Craig JC. Experiences of parents who have children with chronic kidney disease: a systematic review of qualitative studies. Pediatr 2008; 121:349-60. [42] Tong A, Tjaden L, Howard K, Wong G, Morton R, Craig JC. Quality of life of adolescent kidney transplant recipients. J Pediatr 2011; 159:670-5.e2.

[43] Tong A, Wong G, McTaggart S, Henning P, Mackie F, Carroll RP, et al. Quality of life of young adults and adolescents with chronic kidney disease. J Pediatr 2013; 163:1179-85.e5.

[44] Thys K, Schwering KL, Siebelink M, Dobbels F, Borry P, Schotsmans P, et al. Psychosocial impact of pediatric living-donor kidney and liver transplantation on recipients, donors, and the family: a systematic review. Transpl Int 2015; 28:270-80.

[45] Williams K, Thomson D, Seto I, Contopoulos-Ioannidis DG, Ioannidis JP, Curtis S, et al. Standard 6: age groups for pediatric trials. Pediatr 2012; 129 Suppl 3:S153-60.

[46] Zarin DA, Tse T, Williams RJ, Califf RM, Ide NC. The ClinicalTrials.gov results database-update and key issues. N Engl J Med 2011; 364:852-60.

[47] Boers M, Kirwan JR, Wells G, Beaton D, Gossec L, d'Agostino MA, et al. Developing core outcome measurement sets for clinical trials: OMERACT filter 2.0. J Clin Epidemiol 2014; 67:745-53. 
[48] Black N. Patient reported outcome measures could help transform healthcare. BMJ 2013; 346:f167.

[49] Fleming TR, DeMets DL. Surrogate end points in clinical trials: are we being misled? Ann Intern Med 1996; 125:605-13.

[50] Chertow GM, Block GA, Correa-Rotter R, Drueke TB, Floege J, Goodman WG, et al. Effect of cinacalcet on cardiovascular disease in patients undergoing dialysis. N Engl J Med 2012; 367:2482-94.

[51] Halimi JM, Sautenet B, Gatault P, Roland M, Giraudeau B. Renal endpoints in renal and cardiovascular randomized clinical trials: time for a consensus? Fundam Clin Pharmacol 2012; 26:771-82.

[52] Palmer SC, Hayen A, Macaskill P, Pellegrini F, Craig JC, Elder GJ, et al. Serum levels of phosphorus, parathyroid hormone, and calcium and risks of death and cardiovascular disease in individuals with chronic kidney disease: a systematic review and meta-analysis. Jama 2011; 305:1119-27.

[53] Palmer SC, Teixeira-Pinto A, Saglimbene V, Craig JC, Macaskill P, Tonelli M, et al. Association of Drug Effects on Serum Parathyroid Hormone, Phosphorus, and Calcium Levels With Mortality in CKD: A Meta-analysis. Am J Kidney Dis 2015; 66:962-71.

[54] Perkovic V, Neal B. Trials in kidney disease--time to EVOLVE. N Engl J Med 2012; 367:2541-2.

[55] Urquhart-Secord R, Craig JC, Hemmelgarn B, Tam-Tham H, Manns B, Howell M, et al. Patient and Caregiver Priorities for Outcomes in Hemodialysis: An International Nominal Group Technique Study. Am J Kidney Dis 2016.

[56] Sinha IP, Gallagher R, Williamson PR, Smyth RL. Development of a core outcome set for clinical trials in childhood asthma: a survey of clinicians, parents, and young people. Trials 2012; $13: 103$.

[57] Tong A, Henning P, Wong G, McTaggart S, Mackie F, Carroll RP, et al. Experiences and perspectives of adolescents and young adults with advanced CKD. Am J Kidney Dis 2013; 61:375-84.

[58] Nicholas DB, Picone G, Selkirk EK. The lived experiences of children and adolescents with end-stage renal disease. Qual Health Res 2011; 21:162-73.

[59] Sattoe JN, Hilberink SR, Peeters MA, van Staa A. 'Skills for growing up': supporting autonomy in young people with kidney disease. J Ren Care 2014; 40:131-9.

[60] Tjaden L, Tong A, Henning P, Groothoff J, Craig JC. Children's experiences of dialysis: a systematic review of qualitative studies. Arch Dis Child 2012; 97:395-402.

[61] Harman NL, Bruce IA, Kirkham JJ, Tierney S, Callery P, O'Brien K, et al. The Importance of Integration of Stakeholder Views in Core Outcome Set Development: Otitis Media with Effusion in Children with Cleft Palate. PLoS One 2015; 10:e0129514.

[62] Tong A, Morton R, Howard K, Craig JC. Adolescent Experiences Following Organ Transplantation: A Systematic Review of Qualitative Studies. J Pediatr 2009; 155:542-9.e5. [63] Karamanidou C, Weinman J, Horne R. A qualitative study of treatment burden among haemodialysis recipients. J Health Psychol 2014; 19:556-69.

[64] McConachie H, Parr JR, Glod M, Hanratty J, Livingstone N, Oono IP, et al. Systematic review of tools to measure outcomes for young children with autism spectrum disorder. Health Technol Assess 2015; 19.

[65] Hall NJ, Kapadia MZ, Eaton S, Chan WWY, Nickel C, Pierro A, et al. Outcome reporting in randomised controlled trials and meta-analyses of appendicitis treatments in children: a systematic review. Trials $2015 ; 16: 1-14$.

[66] Morris C, Janssens A, Shilling V, Allard A, Fellowes A, Tomlinson R, et al. Meaningful health outcomes for paediatric neurodisability: Stakeholder prioritisation and appropriateness of patient reported outcome measures. Health Qual Life Outcomes 2015; 13:1-9.

[67] Vargus-Adams JN, Martin LK. Measuring what matters in cerebral palsy: a breadth of important domains and outcome measures. Arch Phys Med Rehabil 2009; 90:2089-95. 
[68] Harman NL, Bruce IA, Callery P, Tierney S, Sharif MO, O'Brien K, et al. MOMENT-Management of Otitis Media with Effusion in Cleft Palate: protocol for a systematic review of the literature and identification of a core outcome set using a Delphi survey. Trials 2013; 14:70.

[69] Gargon E, Williamson PR, Altman DG, Blazeby JM, Clarke M. The COMET initiative database: progress and activities update (2014). Trials 2015; 16:1-5.

[70] Tong A, Manns B, Hemmelgarn B, Wheeler DC, Tugwell P, Winkelmayer WC, et al. Standardised outcomes in nephrology - Haemodialysis (SONG-HD): study protocol for establishing a core outcome set in haemodialysis. Trials 2015; 16:1-9.

[71] Tong A, Samuel S, Zappitelli M, Dart A, Furth S, Eddy A, et al. Standardised Outcomes in Nephrology-Children and Adolescents (SONG-Kids): a protocol for establishing a core outcome set for children with chronic kidney disease. Trials 2016; 17:401. 


\section{List of abbreviations}

Chronic kidney disease (CKD)

Randomized controlled trial (RCT)

Quality of life (QOL) 


\section{Figure legends}

Figure 1; online. Search results

Figure 2. Number of trials reporting each outcome domain (total 205 trials, 100 outcome domains)

Figure 3. Number of outcomes measures (definitions and time points) for the most frequently reported and pediatric-specific outcome domains among trials

Figure 4a; online. Frequency of outcomes measures (definitions and time points) among trials reporting blood pressure (76 trials, 56 outcomes measures)

Figure 4b; online. Frequency of outcomes measures (definitions and time points) among trials reporting relapse/remission (67 trials, 82 outcomes measures)

Figure 4c; online. Frequency of outcomes measures (definitions and time points) among trials reporting kidney function (66 trials, 47 outcomes measures)

Figure 4d; online. Frequency of outcomes measures (definitions and time points) among trials reporting infection (61 trials, 114 outcomes measures)

Figure 4e; online. Frequency of outcomes measures (definitions and time points) among trials reporting height and pubertal development (52 trials, 34 outcomes measures

Figure 4f; online. Frequency of outcomes measures (definitions and time points) among trials reporting dermatologic disorder (46 trials, 24 outcomes measures) 
Figure 4g; online. Frequency of outcomes measures (definitions and time points) among trials reporting pain (34 trials, 27 outcomes measures)

Figure 4h; online. Frequency of outcomes measures (definitions and time points) among trials reporting psychological impact (15 trials, 10 outcomes measures)

Figure 4i; online. Frequency of outcomes measures (definitions and time points) among trials reporting weight/BMI/body composition (50 trials, 40 outcomes measures) 
Table 1. Characteristics of included trials $(n=205)$

\begin{tabular}{|c|c|}
\hline Trial characteristic & Number of trials (\%) \\
\hline \multicolumn{2}{|l|}{ Year of publication } \\
\hline$<1980$ & $13(6.3)$ \\
\hline $1980-1989$ & $18(8.8)$ \\
\hline $1990-1999$ & $54(26.3)$ \\
\hline $2000-2009$ & $77(37.6)$ \\
\hline$\geq 2010$ & $43(21.0)$ \\
\hline \multicolumn{2}{|l|}{ Duration of trial (months) } \\
\hline$<3$ & $24(11.7)$ \\
\hline $3-5$ & $26(12.7)$ \\
\hline $6-11$ & $32(15.6)$ \\
\hline $12-23$ & $48(23.4)$ \\
\hline$\geq 24$ & $75(36.6)$ \\
\hline \multicolumn{2}{|l|}{ Sample size (n) } \\
\hline 1 to 50 & $127(62.0)$ \\
\hline 51 to 100 & $39(19.0)$ \\
\hline 101 to 150 & $19(9.3)$ \\
\hline 151 to 200 & $11(5.3)$ \\
\hline$>200$ & $6(2.9)$ \\
\hline Unspecified & $3(1.5)$ \\
\hline \multicolumn{2}{|l|}{ Location } \\
\hline America & $66(32.2)$ \\
\hline Europe & $53(25.9)$ \\
\hline Asia & $51(24.9)$ \\
\hline Africa & $6(2.9)$ \\
\hline Oceania & $1(0.5)$ \\
\hline Multinational studies & $28(13.7)$ \\
\hline
\end{tabular}




\begin{tabular}{|c|c|}
\hline 1 to 5 & $123(52.1)$ \\
\hline Hemodialysis & $32(13.6)$ \\
\hline Peritoneal dialysis & $40(16.9)$ \\
\hline Kidney transplantation & $41(17.4)$ \\
\hline \multicolumn{2}{|l|}{ Primary kidney disease } \\
\hline Nephrotic syndrome & $31(10.3)$ \\
\hline Congenital abnormalities of the kidney and urinary tract (CAKUT) & $25(8.3)$ \\
\hline Focal segmental glomerulosclerosis (FSGS) & $24(8.0)$ \\
\hline Obstructive uropathy & $14(4.7)$ \\
\hline Hemolytic uraemic syndrome (HUS) & $13(4.3)$ \\
\hline Glomerulonephritis & $12(4.0)$ \\
\hline Other & $121(40.2)$ \\
\hline Non-specified & $61(20.3)$ \\
\hline \multicolumn{2}{|l|}{ Intervention type } \\
\hline Immunomodulation & $100(48.8)$ \\
\hline Bone health & $40(19.5)$ \\
\hline Dietary/nutritional & $15(7.3)$ \\
\hline Hematological & $11(6.0)$ \\
\hline Anti-hypertensive agent & $8(3.9)$ \\
\hline Lipid lowering agents & $7(3.4)$ \\
\hline Dialysis-specific & $6(2.9)$ \\
\hline Anti-infective agents & $5(2.4)$ \\
\hline Diuretics & $1(0.5)$ \\
\hline Other & $12(5.9)$ \\
\hline
\end{tabular}

* Multiple categories possible 
Table 2; online only. Proportion of trials reporting each surrogate outcome (205 trials, 51 outcome domains)

\begin{tabular}{|c|c|c|c|}
\hline \multirow{2}{*}{$\begin{array}{l}\text { Domains } \\
\text { (surrogate outcomes) }\end{array}$} & \multicolumn{3}{|c|}{ Number of trials } \\
\hline & All $n=205(\%)$ & Dialysis $n=55(\%)$ & Transplantation $\mathrm{n}=41$ (\%) \\
\hline Blood pressure & $76(37.1)$ & $14(25.5)$ & $17(41.5)$ \\
\hline Relapse/remission & $70(34.1)$ & $1(1.8)$ & $1(2.4)$ \\
\hline Kidney function & $66(32.2)$ & $5(9.1)$ & $3(7.3)$ \\
\hline Weight/BMI/body composition & $50(24.4)$ & $7(12.7)$ & $12(29.3)$ \\
\hline Proteinuria, albuminuria & $49(23.9)$ & $2(3.6)$ & $3(7.3)$ \\
\hline Blood protein, albumin & $48(23.4)$ & $9(16.4)$ & $3(7.3)$ \\
\hline Lipids & $47(22.9)$ & $6(10.9)$ & $16(39.0)$ \\
\hline Anemia/haemoglobin/iron & $44(21.5)$ & $15(27.3)$ & $8(20.0)$ \\
\hline Phosphate & $39(19.0)$ & $21(38.2)$ & $7(17.1)$ \\
\hline White blood cells & $39(19.0)$ & $1(1.8)$ & $8(19.5)$ \\
\hline Bone density/markers & $37(18.0)$ & $17(30.9)$ & $7(17.1)$ \\
\hline Calcium & $34(16.6)$ & $18(32.7)$ & $6(14.6)$ \\
\hline Urea & $31(15.1)$ & $8(14.5)$ & $4(9.8)$ \\
\hline Glucose metabolism & $31(15.1)$ & $9(16.4)$ & $16(39.0)$ \\
\hline Parathyroid hormone & $31(15.1)$ & $18(32.7)$ & $6(14.6)$ \\
\hline Graft function & $30(14.6)$ & & $30(73.2)$ \\
\hline Electrolytes (other) & $25(12.2)$ & $5(9.1)$ & $8(19.5)$ \\
\hline Liver function & $24(11.7)$ & $3(5.5)$ & $4(9.8)$ \\
\hline Potassium & $22(10.7)$ & $6(10.9)$ & $4(9.8)$ \\
\hline Acute graft rejection & $20(9.8)$ & $2(3.6)$ & $20(48.8)$ \\
\hline Inflammatory markers/oxidative stress & $19(9.3)$ & $6(10.9)$ & $6(14.6)$ \\
\hline Acid-base balance & $25(12.2)$ & $11(20.0)$ & $4(9.8)$ \\
\hline Vitamin D & $15(7.3)$ & $9(16.4)$ & $2(4.9)$ \\
\hline Dialysis adequacy & $13(6.3)$ & $13(23.6)$ & - \\
\hline Platelets, coagulation & $14(6.8)$ & $3(5.5)$ & $2(4.9)$ \\
\hline Kidney disease progression/change & $12(5.9)$ & $1(1.8)$ & $1(2.4)$ \\
\hline Graft rejection (unspecified) & $11(5.4)$ & - & $11(26.8)$ \\
\hline
\end{tabular}




\begin{tabular}{|c|c|c|c|}
\hline Growth hormone & $11(5.4)$ & $5(9.1)$ & $5(12.2)$ \\
\hline Respiratory function & $11(5.4)$ & $3(5.5)$ & $4(9.8)$ \\
\hline Acute kidney injury & $9(4.4)$ & - & $1(2.4)$ \\
\hline Serum immunoglobulins & $9(4.4)$ & $1(1.8)$ & $1(2.4)$ \\
\hline Calcium x Phosphate & $9(4.4)$ & $6(10.9)$ & - \\
\hline Graft histology/ pathology (excl. rejection) & $8(3.9)$ & - & $8(19.5)$ \\
\hline Uric acid & $8(3.9)$ & $1(1.8)$ & - \\
\hline Caloric intake & $8(3.9)$ & $4(7.3)$ & - \\
\hline Protein intake & $7(3.4)$ & $3(5.5)$ & - \\
\hline Electrolyte intake & $7(3.4)$ & $5(9.1)$ & - \\
\hline Renal tubular dysfunction & $6(2.9)$ & $3(5.5)$ & - \\
\hline Fertility & $5(2.4)$ & $2(3.6)$ & - \\
\hline Cardiac function & $5(2.4)$ & $1(1.8)$ & - \\
\hline Rhabdomyolysis & $5(2.4)$ & $1(1.8)$ & $2(4.9)$ \\
\hline Endocrine function & $4(2.0)$ & $1(1.8)$ & $1(2.4)$ \\
\hline Nitrates & $3(1.5)$ & $1(1.8)$ & $1(2.4)$ \\
\hline Thyroid function & $3(1.5)$ & $1(1.8)$ & $1(2.4)$ \\
\hline Amino acids & $3(1.5)$ & $2(3.6)$ & - \\
\hline Aluminium toxicity & $2(1.0)$ & $1(1.8)$ & - \\
\hline Urine volume & $2(1.0)$ & $1(1.8)$ & - \\
\hline Blood pressure regulating hormone & $2(1.0)$ & - & - \\
\hline Carnitine & $2(1.0)$ & $2(3.6)$ & - \\
\hline Chronic graft rejection & $2(1.0)$ & - & $2(4.9)$ \\
\hline Vitamin $\mathrm{E}$ & $1(0.5)$ & - & - \\
\hline Donor-specific anti-HLA antibody & $1(0.5)$ & - & $1(2.4)$ \\
\hline
\end{tabular}

-, no trials reported 
Table 3; online only. Proportion of trials reporting each clinical outcome (205 trials, 38 outcome domains)

\begin{tabular}{|c|c|c|c|}
\hline \multirow{2}{*}{$\begin{array}{l}\text { Domains } \\
\text { (clinical outcomes) }\end{array}$} & \multicolumn{3}{|c|}{ Number of trials } \\
\hline & All $n=205(\%)$ & Dialysis $\mathrm{n}=55$ (\%) & Transplantation $\mathrm{n}=41$ (\%) \\
\hline Infection & $61(29.8)$ & $17(30.9)$ & $16(39.0)$ \\
\hline Height and pubertal development & $51(24.9)$ & $12(21.8)$ & $18(43.9)$ \\
\hline Dermatologic disorder & $46(22.4)$ & $5(9.1)$ & $4(9.8)$ \\
\hline Gastrointestinal effects & $43(21.0)$ & $7(12.7)$ & $8(19.5)$ \\
\hline Adverse events (non-specified) & $36(17.6)$ & $6(10.9)$ & $10(24.4)$ \\
\hline Mortality & $28(13.7)$ & $3(5.5)$ & $15(36.6)$ \\
\hline Neurologic disorders & $26(12.7)$ & $3(5.5)$ & $6(14.6)$ \\
\hline Urologic complication & $23(11.2)$ & $2(3.6)$ & $6(14.6)$ \\
\hline Respiratory disease & $22(10.7)$ & $4(7.3)$ & $6(14.6)$ \\
\hline Graft loss & $19(9.3)$ & - & $19(46.3)$ \\
\hline Vision disorder & $18(8.8)$ & $2(3.6)$ & $1(2.4)$ \\
\hline Mouth and gum disorders & $14(6.8)$ & - & $3(7.3)$ \\
\hline Bone disease/fractures & $14(6.8)$ & $4(7.3)$ & $5(12.2)$ \\
\hline Cushing syndrome & $14(6.8)$ & - & $1(2.4)$ \\
\hline Cardiovascular disease & $8(3.9)$ & $4(7.3)$ & $1(2.4)$ \\
\hline Dialysis treatment complications & $8(3.9)$ & $7(12.7)$ & $2(4.9)$ \\
\hline Malignancy - PTLD & $8(3.9)$ & - & $8(19.5)$ \\
\hline Malignancy (unspecified) & $6(2.9)$ & $1(1.8)$ & $3(7.3)$ \\
\hline Edema & $6(2.9)$ & $2(3.6)$ & - \\
\hline Hospitalization & $6(2.9)$ & $1(1.8)$ & $4(9.8)$ \\
\hline Procedural complication & $5(2.4)$ & - & $1(2.4)$ \\
\hline Allergic reaction & $5(2.4)$ & $3(5.5)$ & - \\
\hline Bleeding/hematoma & $5(2.4)$ & $1(1.8)$ & $1(24)$ \\
\hline Muscular complications & $5(2.4)$ & $1(1.8)$ & $3(7.3)$ \\
\hline Requirement of transplantation & $4(2.0)$ & $2(3.6)$ & - \\
\hline Fever/chills & $4(2.0)$ & $2(3.6)$ & $2(4.9)$ \\
\hline Compliance & $4(2.0)$ & $3(5.5)$ & $1(2.4)$ \\
\hline
\end{tabular}




\begin{tabular}{|c|c|c|c|}
\hline Time on dialysis & $3(1.5)$ & $1(1.8)$ & $2(4.9)$ \\
\hline Metabolic and nutritional disorders & $3(1.5)$ & - & $1(2.4)$ \\
\hline End stage kidney disease & $3(1.5)$ & - & - \\
\hline Dehydration & $2(1.0)$ & - & $2(4.9)$ \\
\hline Arthritis and joint pain & $2(1.0)$ & - & - \\
\hline Hearing impairment & $2(1.0)$ & $1(1.8)$ & - \\
\hline Physical injury & $2(1.0)$ & $1(1.8)$ & - \\
\hline Vascular access complications & $1(0.5)$ & $1(1.8)$ & - \\
\hline Malignancy - skin & $1(0.5)$ & - & $1(2.4)$ \\
\hline Pulmonary embolus & $1(0.5)$ & - & - \\
\hline Hyperhidrosis & $1(0.5)$ & - & - \\
\hline
\end{tabular}


Table 4; online only. Proportion of trials reporting each patient-reported outcome (205 trials, 10 outcome domains)

\begin{tabular}{|c|c|c|c|}
\hline \multirow{2}{*}{$\begin{array}{l}\text { Domains } \\
\text { (patient-reported outcomes) }\end{array}$} & \multicolumn{3}{|c|}{ Number of trials } \\
\hline & Total trials, $\mathrm{n}=205$ (\%) & Dialysis trials, $\mathrm{n}=55(\%)$ & $\begin{array}{l}\text { Transplantation trials, } \\
\qquad n=41(\%)\end{array}$ \\
\hline Pain & $33(16.1)$ & $12(21.8)$ & $5(12.2)$ \\
\hline Psychological impact & $15(7.3)$ & $1(1.8)$ & - \\
\hline Treatment satisfaction & $2(1.0)$ & $1(1.8)$ & $1(2.4)$ \\
\hline Sleep disorder & $2(1.0)$ & $1(1.8)$ & - \\
\hline Fatigue & $2(1.0)$ & - & - \\
\hline Quality of life (global) & $2(1.0)$ & $1(1.8)$ & - \\
\hline Depression & $2(1.0)$ & $1(1.8)$ & - \\
\hline Food enjoyment/appetite & $2(1.0)$ & $1(1.8)$ & - \\
\hline School performance & $1(0.5)$ & $1(1.8)$ & - \\
\hline Physical function/mobility/ disability & $1(0.5)$ & $1(1.8)$ & - \\
\hline
\end{tabular}


Table 5. Proportion of trials reporting the top 10 most frequently reported outcome domains

\begin{tabular}{lccc}
\hline Domains & \multicolumn{3}{c}{ Number of trials } \\
\cline { 2 - 4 } (all outcomes) & All $\mathbf{n = 2 0 5 ( \% )}$ & Dialysis $\mathbf{n = 5 5 ( \% )}$ & Transplantation n=41 (\%) \\
\hline Blood pressure & $76(37.1)$ & $14(25.5)$ & $17(41.5)$ \\
\hline Relapse/remission & $70(34.1)$ & $1(1.8)$ & $1(2.4)$ \\
\hline Kidney function & $66(32.2)$ & $5(9.1)$ & $3(7.3)$ \\
\hline Infection & $61(29.8)$ & $17(30.9)$ & $16(39.0)$ \\
\hline Height and pubertal development & $51(24.9)$ & $12(21.8)$ & $18(43.9)$ \\
\hline Weight/BMl/body composition & $50(24.4)$ & $7(12.7)$ & $12(29.3)$ \\
\hline Proteinuria, albuminuria & $49(23.9)$ & $2(3.6)$ & $3(7.3)$ \\
\hline Blood protein, albumin & $48(23.4)$ & $9(16.4)$ & $16(39.0)$ \\
\hline Lipids & $47(22.9)$ & $6(10.9)$ & $4(9.8)$ \\
\hline Dermatologic disorder & $46(22.4)$ & $5(9.1)$ & \\
\hline
\end{tabular}


Table 6; online only. Primary outcomes reported in trials conducted in children with CKD

\begin{tabular}{|c|c|}
\hline Domains of primary outcomes (96 trials*) & Number of trials (\%) \\
\hline Relapse/remission & $43(44.8)$ \\
\hline Proteinuria, albuminuria & $22(22.9)$ \\
\hline Kidney function & $18(18.8)$ \\
\hline Height and pubertal development & $15(15.6)$ \\
\hline Anemia/haemoglobin/iron & $9(9.4)$ \\
\hline Bone density/markers & $6(6.3)$ \\
\hline Acute graft rejection & $5(5.2)$ \\
\hline Adverse events & $5(5.2)$ \\
\hline Glucose metabolism & $5(5.2)$ \\
\hline Infection & $5(5.2)$ \\
\hline Lipids & $5(5.2)$ \\
\hline Parathyroid hormone & $4(4.2)$ \\
\hline Pain & $3(3.1)$ \\
\hline Kidney disease progression/change & $3(3.1)$ \\
\hline Dialysis adequacy & $3(3.1)$ \\
\hline Cardiac function & $2(2.1)$ \\
\hline Cushing's syndrome & $2(2.1)$ \\
\hline Urologic complication & $2(2.1)$ \\
\hline Phosphate & $2(2.1)$ \\
\hline Graft rejection (unspecified) & $2(2.1)$ \\
\hline Other & $14(14.6)$ \\
\hline
\end{tabular}

* 96 out of 205 trials reported primary outcomes 

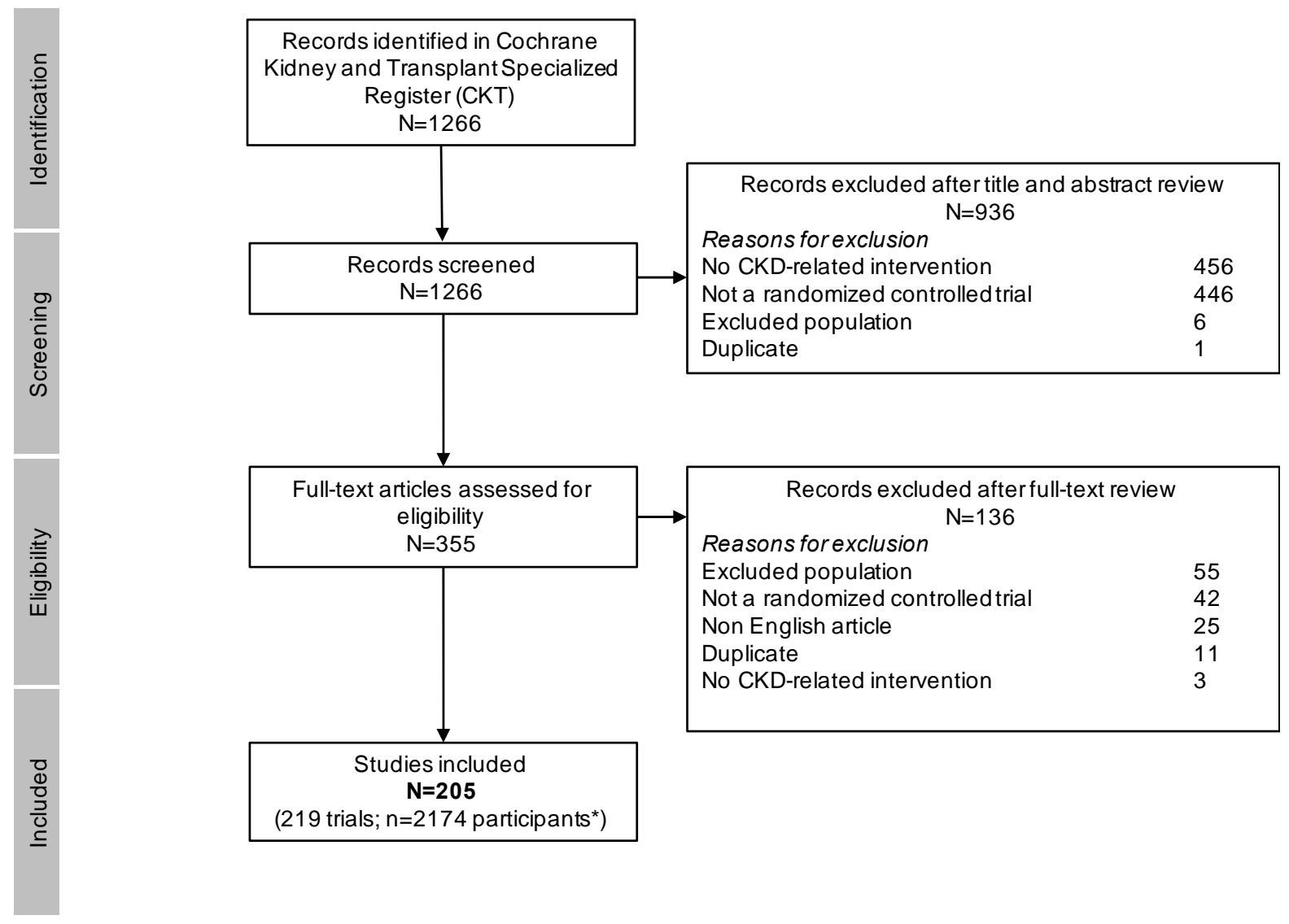

*Sample size not included in 3 studies 


\section{Figure 2}

Click here to download Figure: SONG Kids SR - JPQdstcagmes. Ppexnains $(n=100)$

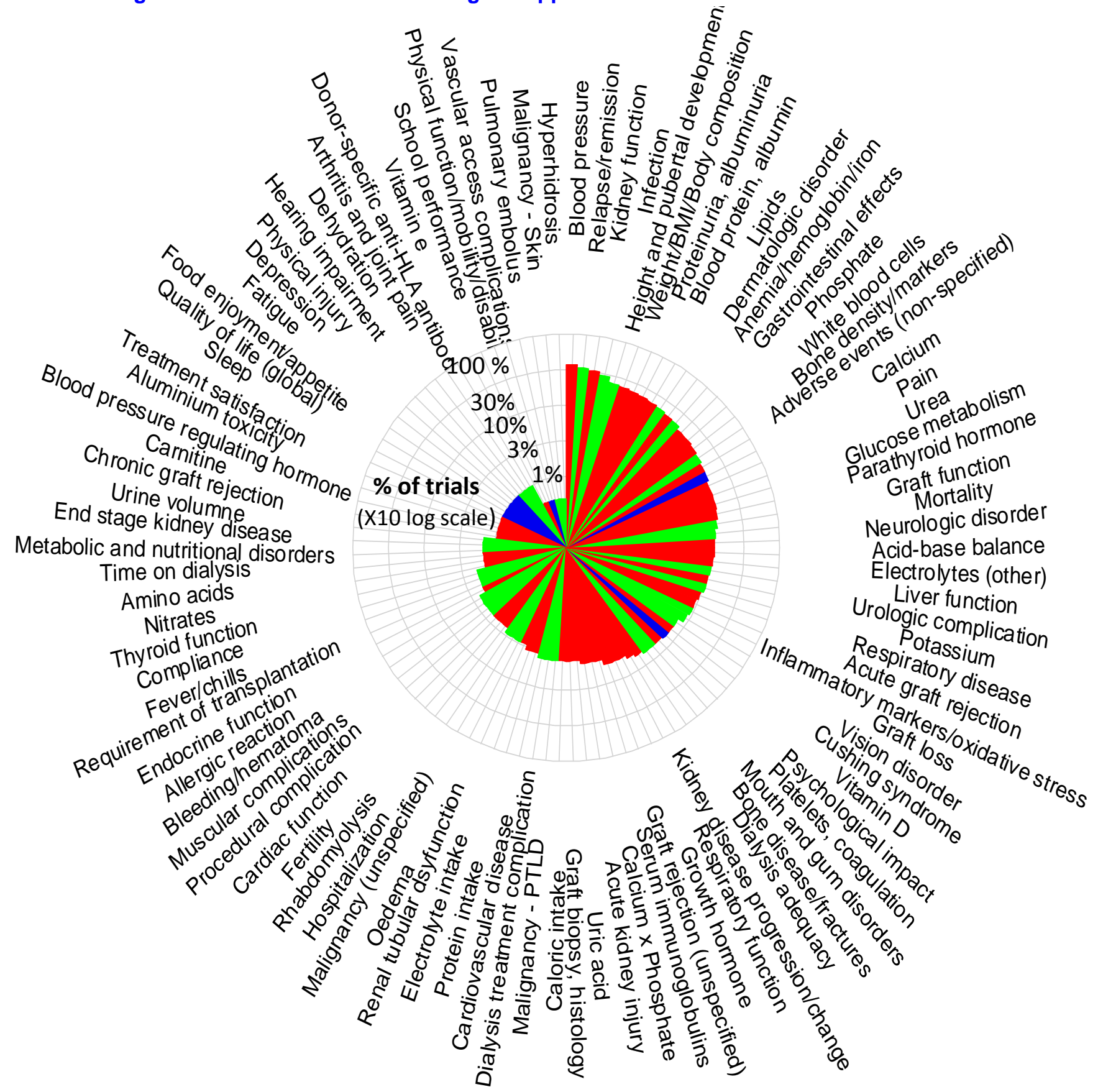




\section{Categories of outcome:}

Surrogate $(n=52)$

Clinical $(n=38)$

Patient reported, $(n=10)$

NB: Proportion are expressed in a $\times 10$

log scale to display proportion $<1 \%$ 
Figure 3

Click here to download Figure: SONG Kids SR - JPeds - Figure 3.docx

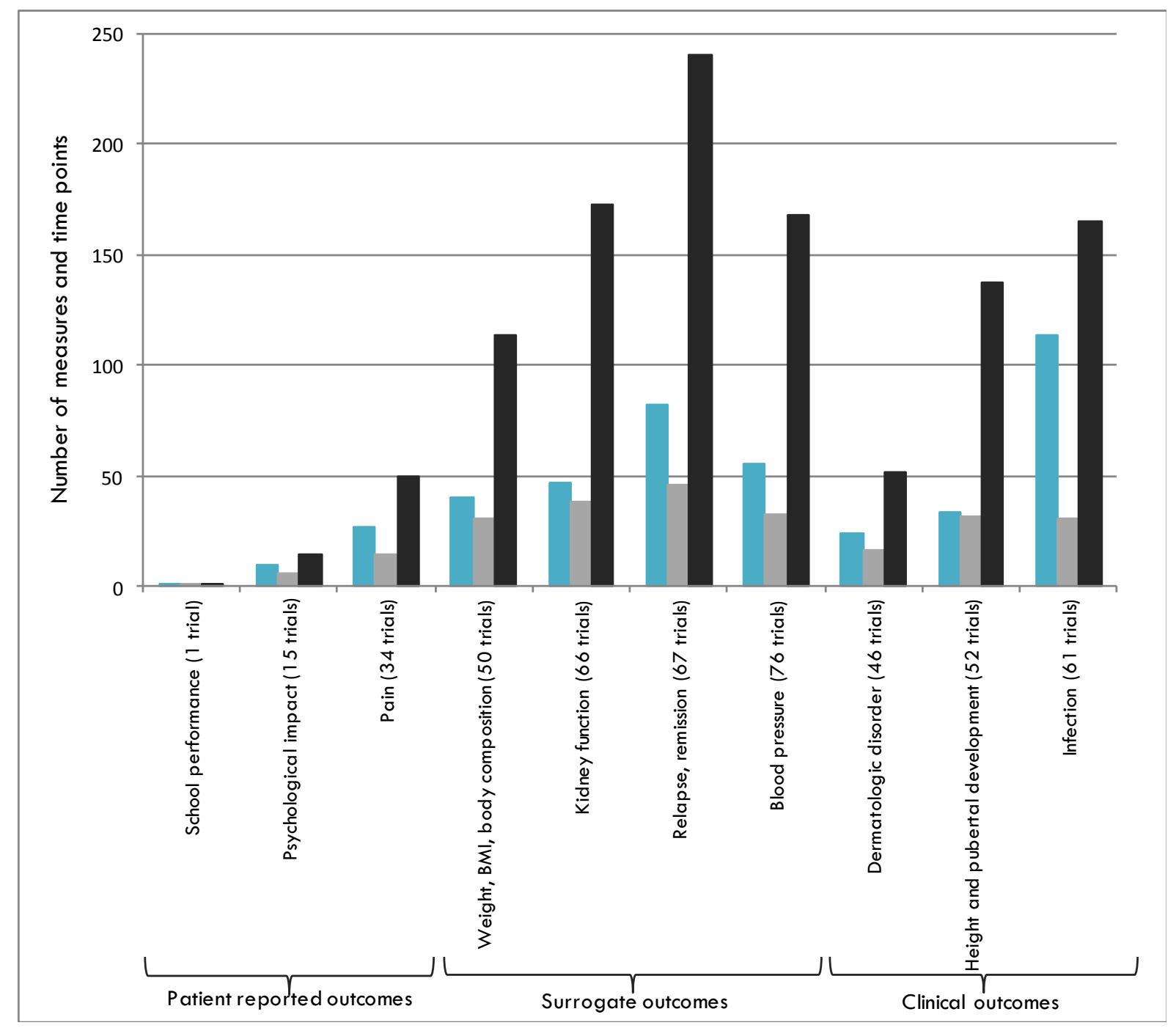




\section{Figure Legend}

Number of measures

Number of time points *

Number of measures and time points **

* Number of unique time points

**Different measures can have the same time points 


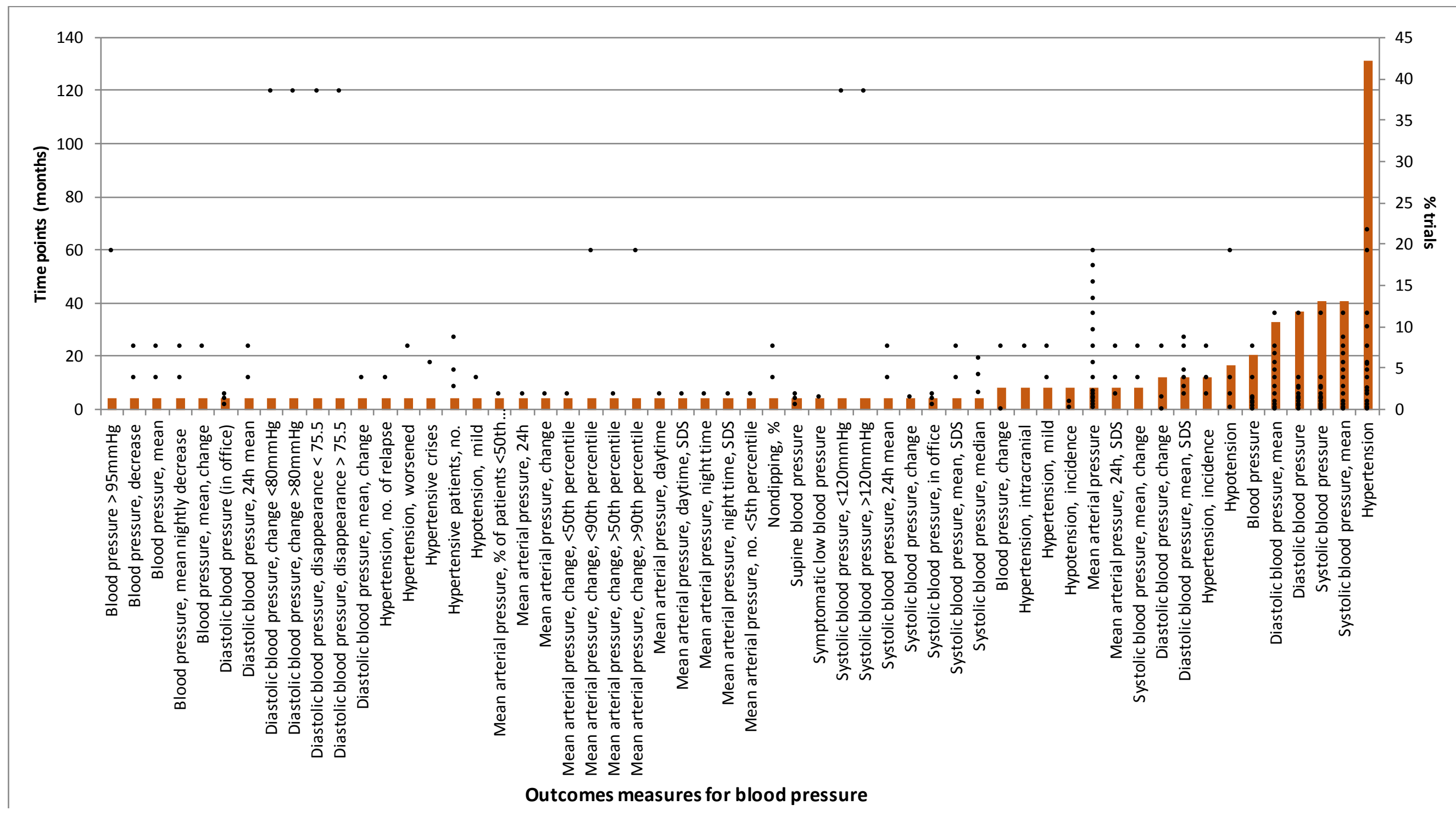




\section{Proportion of trials \\ - Time points of measurement}

* Outcome measures shown are as named in the trials 


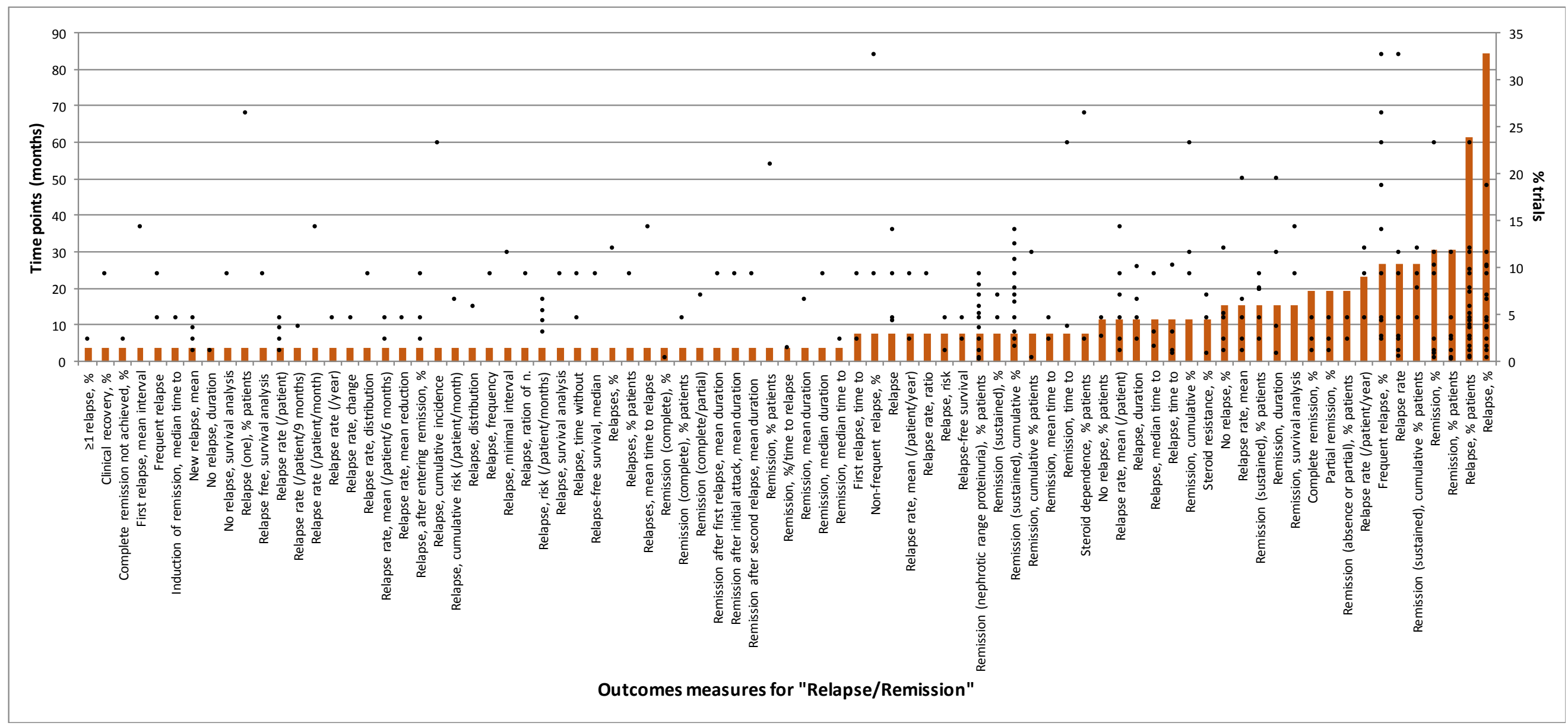




\section{Proportion of trials}

- Time points of measurement

* Outcome measures shown are as named in the trials 


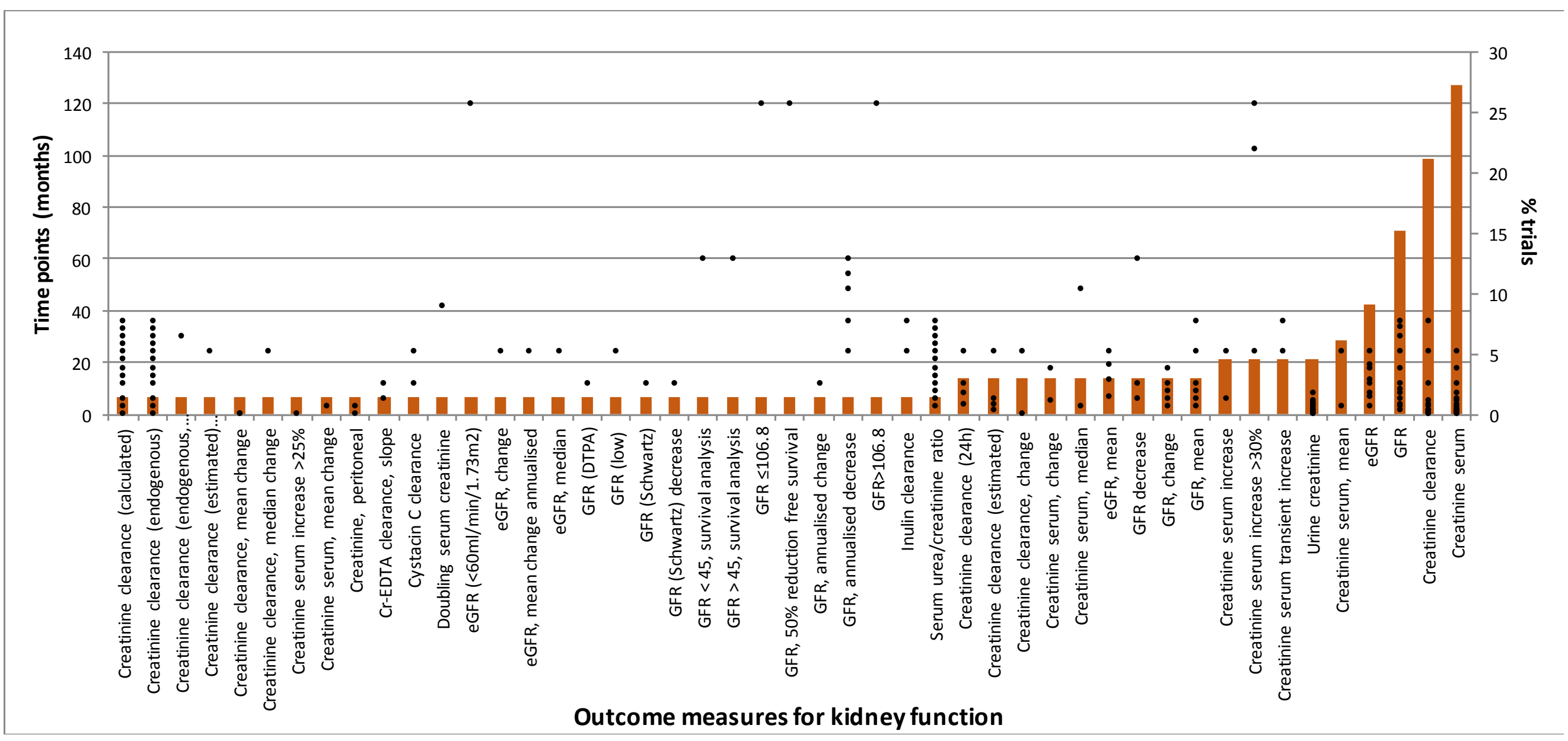




\section{Proportion of trials}

- Time points of measurement

* Outcome measures shown are as named in the trials 
Click here to download Figure: SONG Kids SR - JPeds - Figure 4d (online).docx

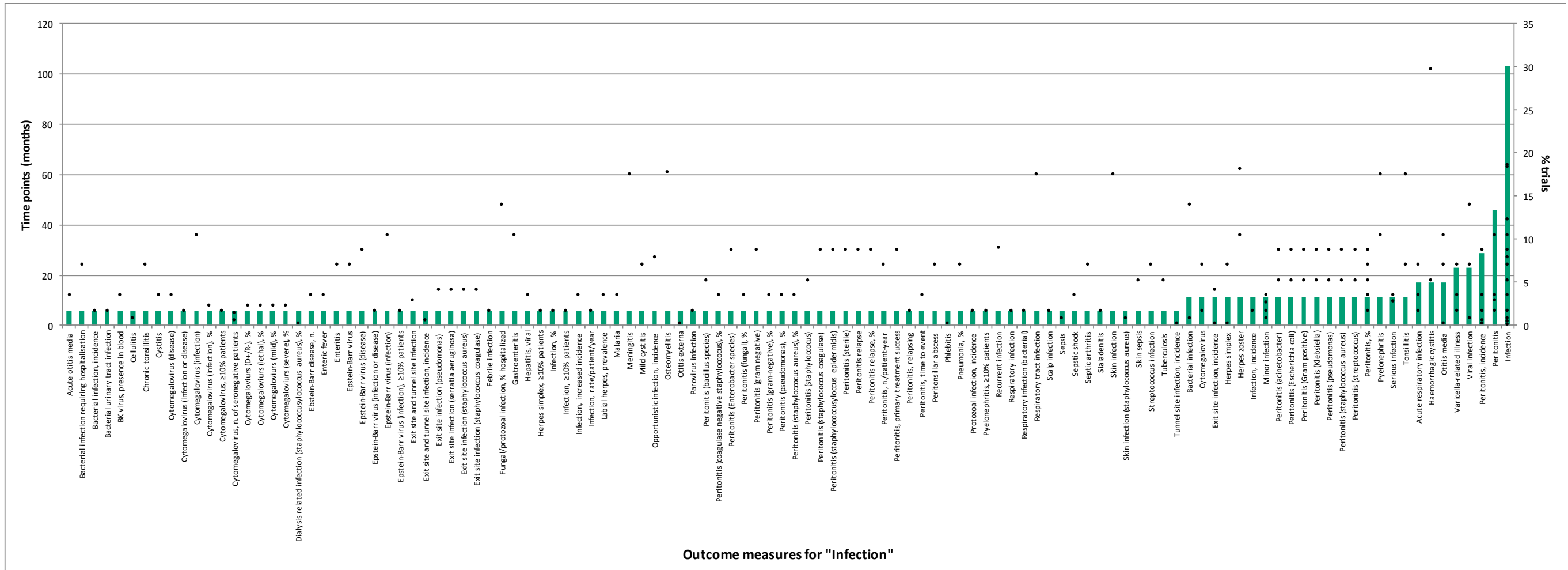




\section{Proportion of trials
- Time points of measurement}

* Outcome measures shown are as named in the trials 


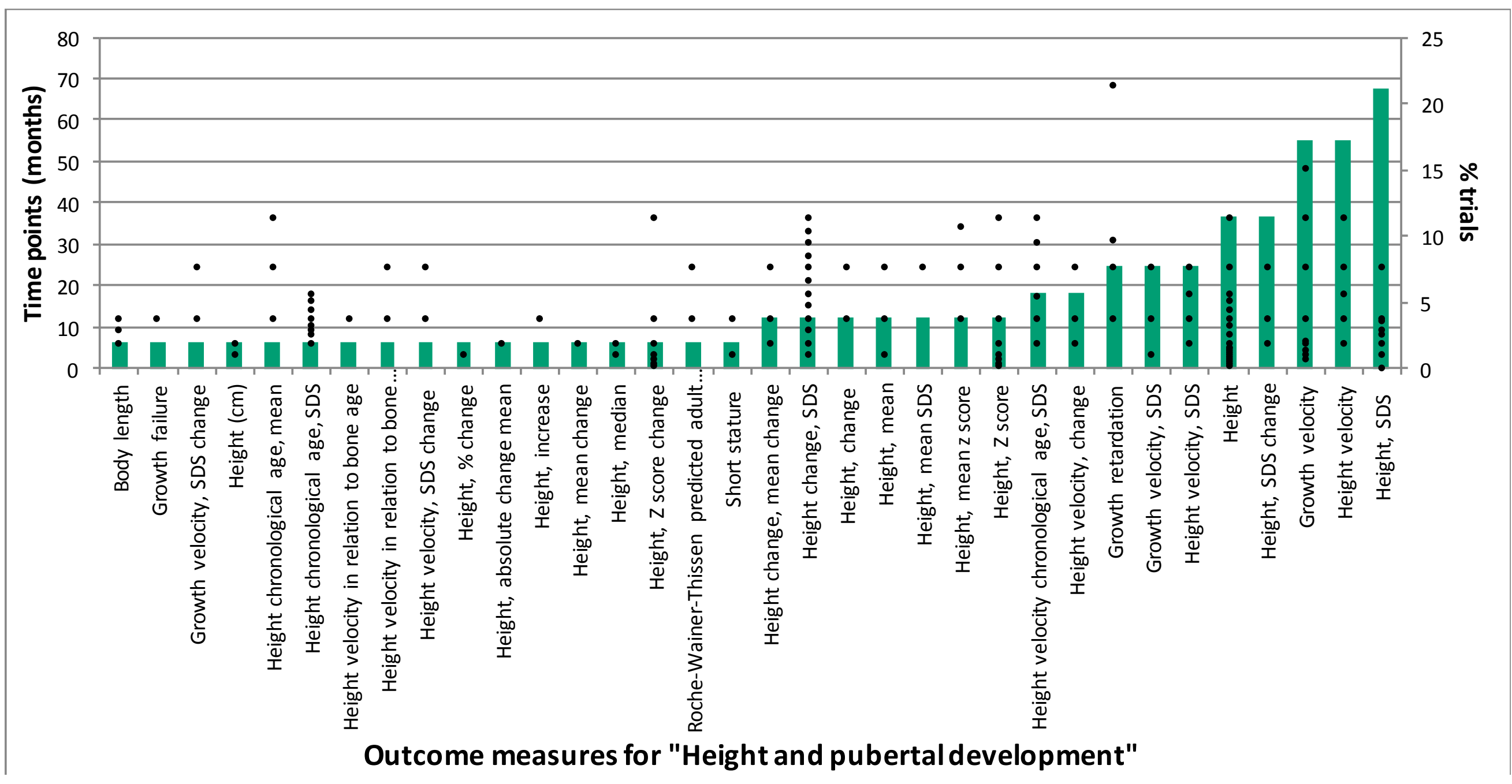




\section{Proportion of trials}

- Time points of measurement

* Outcome measures shown are as named in the trials 


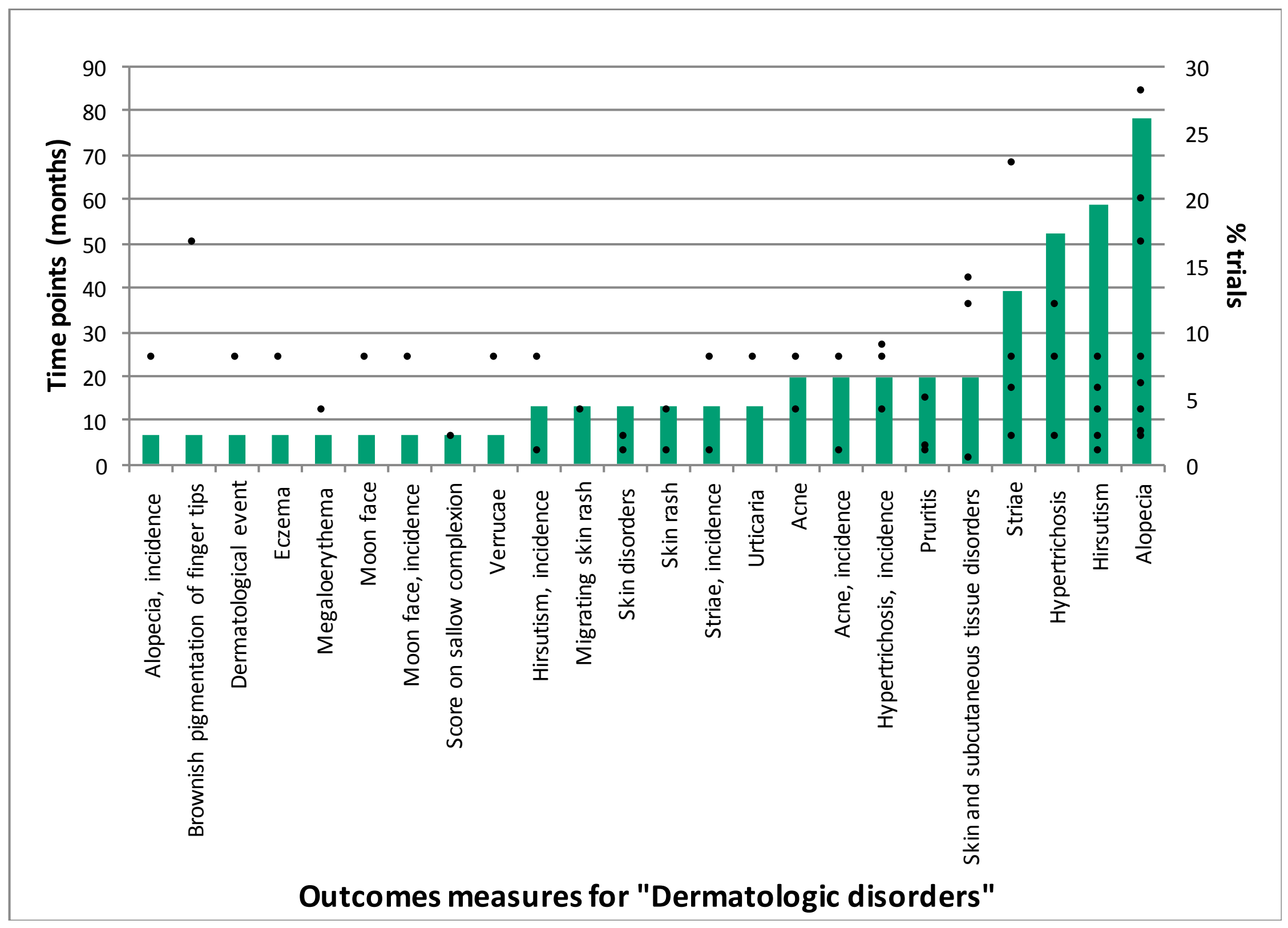




\section{Proportion of trials}

Time points of measurement

* Outcome measures shown are as named in the trials 


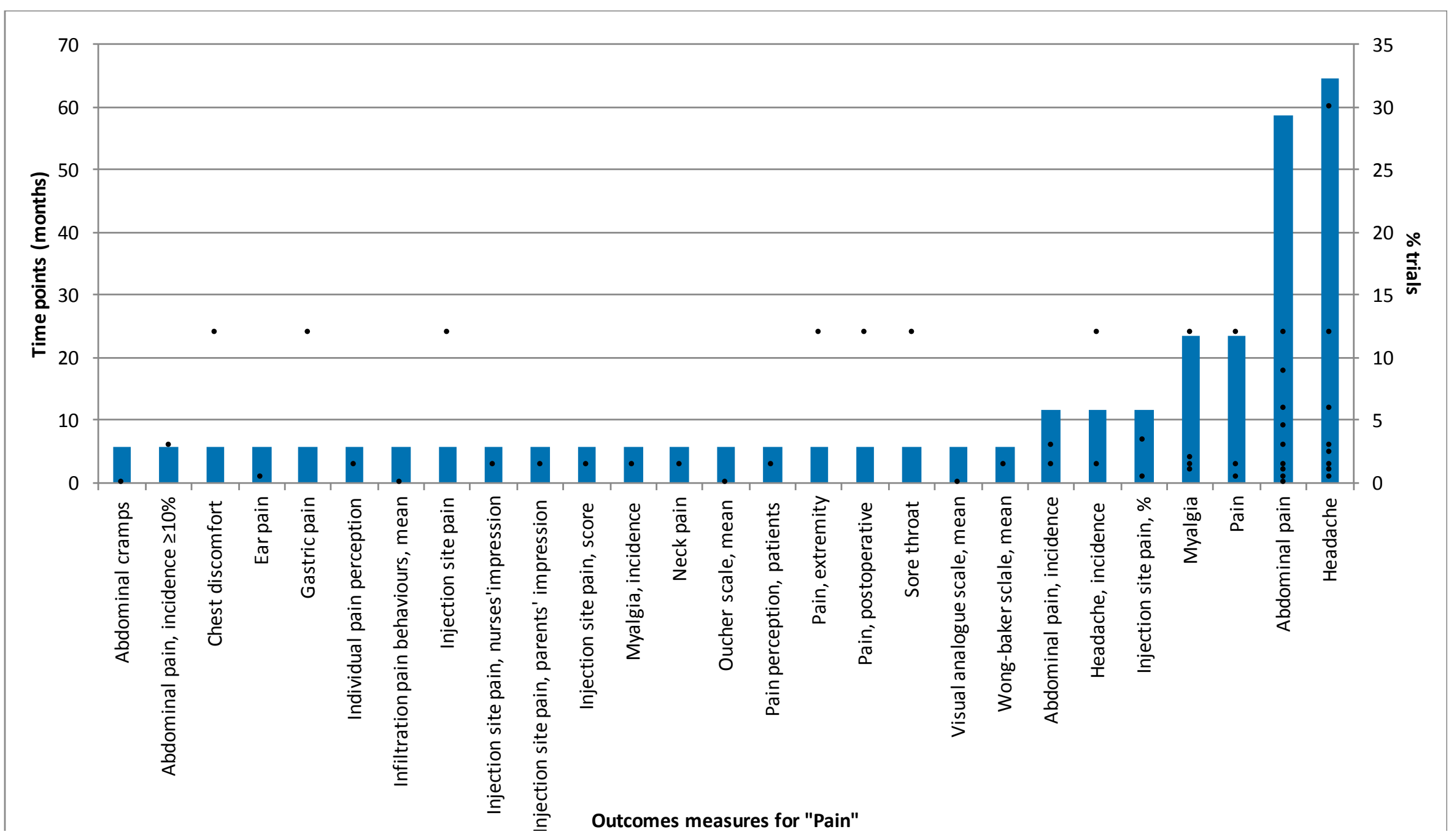




\section{Proportion of trials}

- Time points of measurement

* Outcome measures shown are as named in the trials 


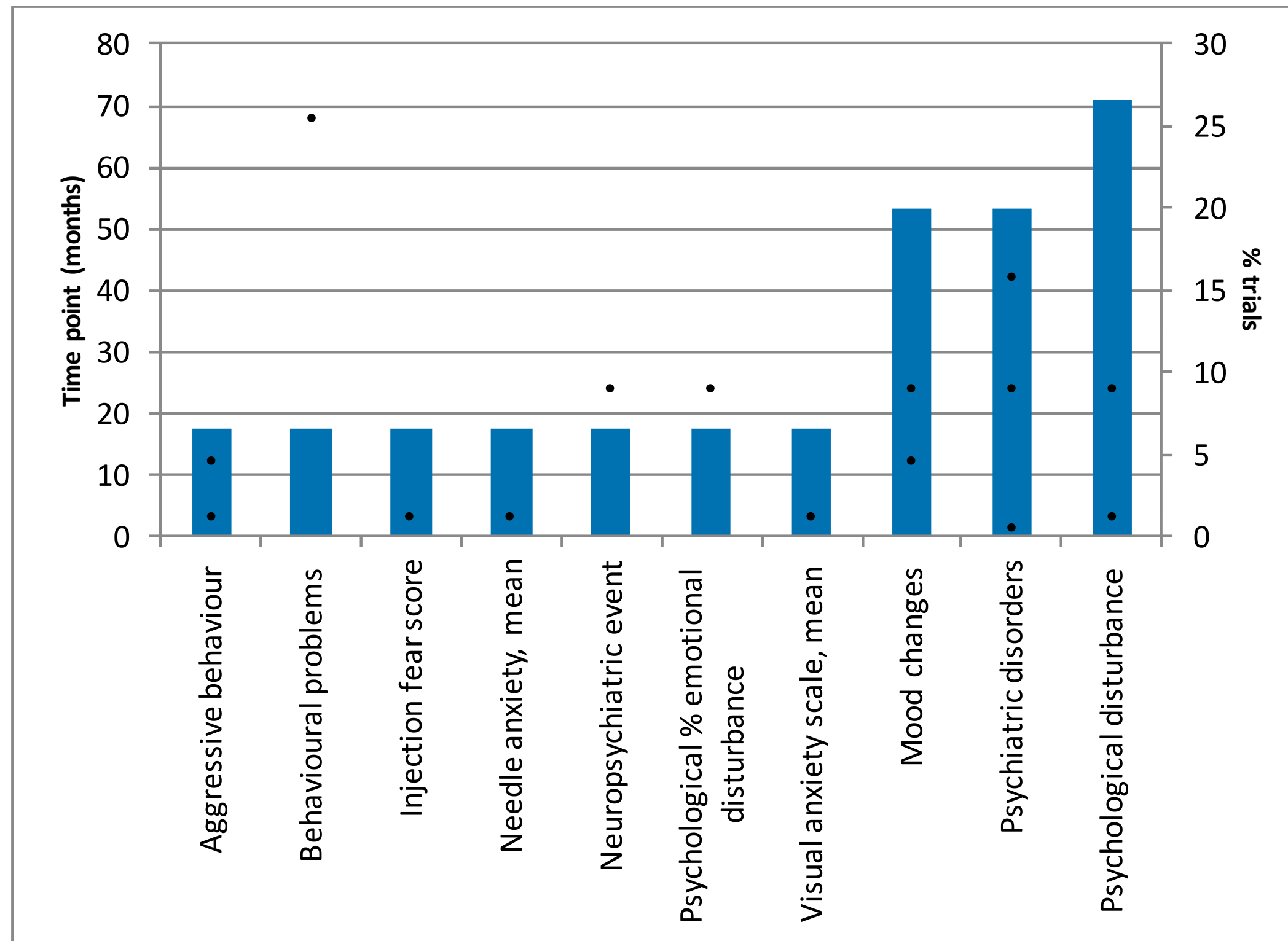

Outcomes measures for "Psychological impact" 


\section{Proportion of trials}

- Time points of measurement

* Outcome measures shown are as named in the trials 


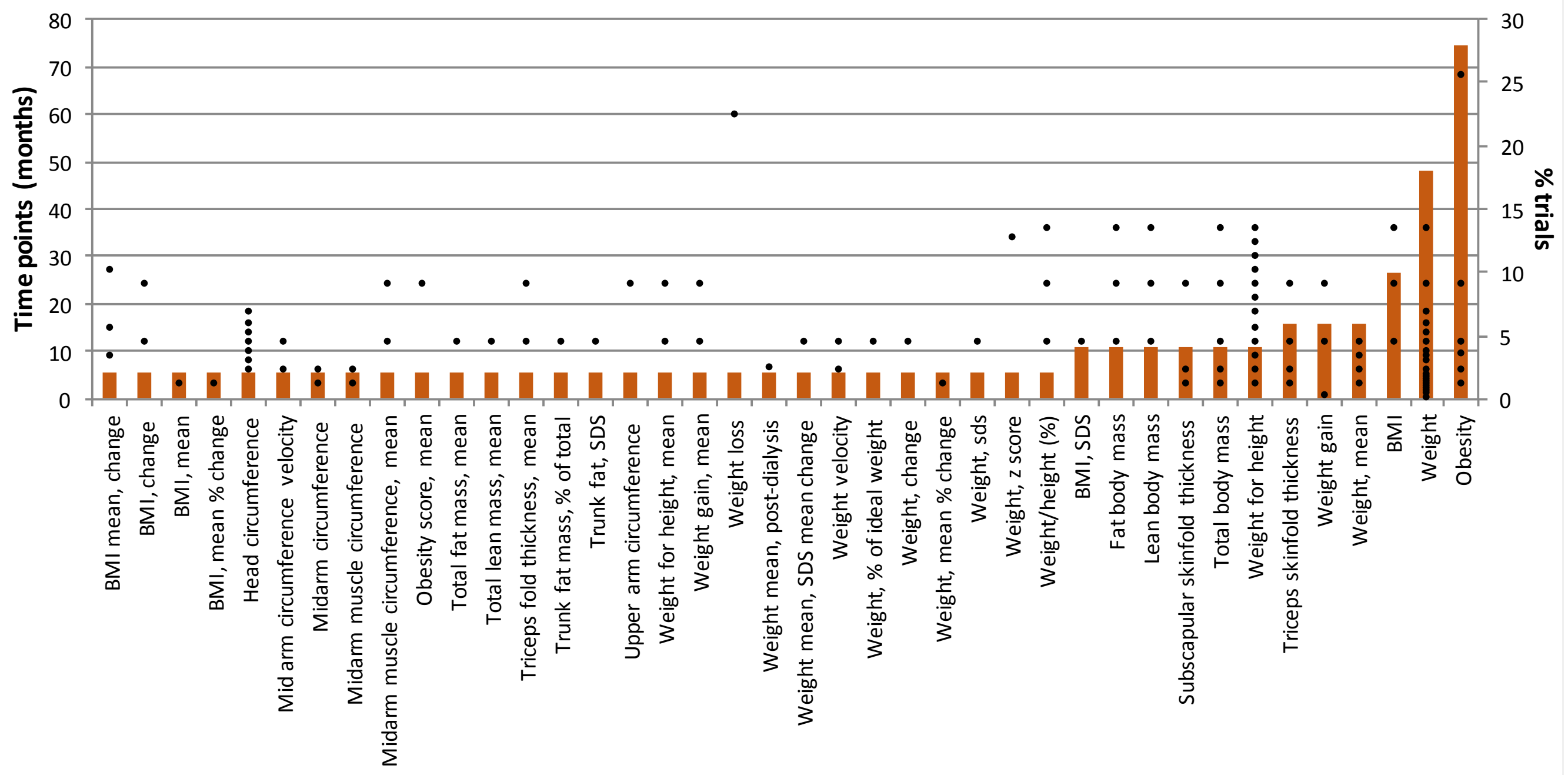

Outcomes measures for "Weight, BMI, body composition" 


\section{Proportion of trials}

- Time points of measurement

* Outcome measures shown are as named in the trials 